\title{
STUDI PENGELOLAAN SAMPAH DI RUMAH SAKIT UMUM DAERAH AJIBARANG KABUPATEN BANYUMAS TAHUN 2015
}

\author{
Setyo Amonggoro' ${ }^{1)}$, Priyo Santoso ${ }^{2)}$ \\ Jurusan Kesehatan Lingkungan, Politeknik Kesehatan Kemenkes Semarang, \\ Jl. Raya Baturaden KM 12 Purwokerto, Indonesia
}

\begin{abstract}
Abstrak
Rumah Sakit sebagai sarana pelayanan kesehatan dan tempat berkumpulnya orang sakit maupun orang sehat, serta dapat menjadi tempat penularan penyakit dan memungkinkan terjadinya pencemaran lingkungan maupun gangguan kesehatan. RSUD Ajibarang adalah Rumah Sakit kelas C yang memiliki 163 tempat tidur inap dan memiliki BOR (Bed Occupancy Rate) di RSUD Ajibarang pada tahun 2014 sebesar 56,41\%. Penelitian ini bertujuan untuk mengetahui sistem pengelolaan sampah di RSUD Ajibarang Kabupaten Banyumas. Jenis penelitian ini menggunakan metode deskriptif. Data dikumpulkan dengan cara observasi, wawancara dan pengukuran. Hasil penelitian pengelolaan sampah di RSUD Ajibarang Kabupaten Banyumas volume sampah medis rata-rata perhari adalah 736,27 liter dan untuk sampah non medis adalah 1958,125 liter per hari dan skor penilaian sampah medis yang didapatkan yaitu $89 \%$ dan sampah non medis $77 \%$. Sudah dilakukannya pemisahan antara sampah medis dengan sampah non medis, namun masih tercampurnya sampah organik dengan anorganik pada sampah non medisnya. Dan masih tercampur antara sampah infeksius benda tajam dengan sampah infeksius lainnya. Pengangkutan sampah medis dan non medis dilakukan oleh petugas dengan cara manual.
\end{abstract}

Kata Kunci : sampah, rumah sakit

\begin{abstract}
Hospital as a health-care facility and a gathering place of the sick and healthy people, and can be a transmission of the disease and allow for environmental pollution and health problems. General Hospital Ajibarang is a hospital type $C$ which has 163 inpantient beds in hospital and have BOR (Bed Occupancy Rate) in 2014 amounted to 56,41\%. This study aims to determine the waste management system in general hospital ajibarang banyumas district. This type of research uses descriptive method. Data collected by observation, interview and measurement. The results of waste management in hospitals ajibarang. Average volume of medical waste is 736,27 liter, and for non medical waste is 1958,125 liter. And medical gerbage assessmen scores were obtained, namely $89 \%$ and $77 \%$ of non medical waste. Already done separation between medical garbage with non medical gerbage, but still mixing organic gerbage with anorganic gerbage on non medical gerbage. And still mixed among infectious sharps bins with trash other infectious. Transport of medical and non medical gerbage is done by the officer by means of manual.
\end{abstract}

Keywords : garbage, hospitals

\section{Pendahuluan}

Pembangunan yang dilaksanakan di Indonesia salah satunya adalah pembangunan di bidang kesehatan. Pembangunan kesehatan bertujuan untuk meningkatkan kesadaran, kemauan, dan kemampuan hidup sehat bagi setiap orang agar terwujud derajat kesehatan masyarakat yang setinggi tingginya. Sebagai investasi pembangunan, bagi sumber daya manusia yang produktif secara sosial dan ekonomis (UU kesehatan No 36 pasal 3 tahun 2009).

Rumah Sakit sebagai sarana, pelayanan kesehatan dan tempat berkumpulnya orang sakit maupun orang sehat, serta dapat menjadi tempat penularan penyakit dan memungkinkan terjadinya pencemaran lingkungan maupun gangguan kesehatan. Dalam aktifitasnya rumah sakit akan menghasilkan limbah padat atau sampah. Secara garis besar limbah padat atau sampah Rumah Sakit dibedakan menjadi dua macam, yaitu sampah non medis dan sampah medis. (Kepmenkes R.I.No. 1204/Menkes/SK/X/2004,h.1)

Sampah non medis adalah sampah yang dihasilkan dari kegiatan rumah sakit yang berasal dari dapur, perkantoran, taman dan halaman yang dapat dimanfaatkan kembali apabila ada teknologinya. Sedangkan sampah medis adalah sampah yang terdiri dari limbah infeksius, limbah patologi, limbah benda tajam, limbah farmasi, limbah sitotoksis, limbah kimiawi.Limbah radioaktif, limbah 
kontainer bertekanan dan limbah dengan kandungan logam berat yang tinggi. (Kepmenkes R.I. No.1204/Menkes/SK/X/2004, h.19)

Sampah Rumah Sakit harus dikelola dengan cara yang saniter, dimulai dari titik penimbulan sampai dengan pemusnahan/ pembuangan akhirnya. Pengelolaan sampah medis dan non medis Rumah Sakit harus memenuhi syarat sanitasi, karena berbagai jenis sampah medis dan non medis yang dihasilkan di rumah sakit bisa membahayakan dan menimbulkan gangguan kesehatan bagi pengunjung terutama petugas yang menangani pengelolaan sampah, serta masyarakat disekitar Rumah Sakit. (Departemen Kesehatan RI,1992, h.67)

Berbagai jenis sampah atau limbah yang di hasilkan oleh Rumah Sakit sangat berpotensi untuk menyebabkan gangguan dalam kehidupan dan kesehatan manusia serta lingkungannya. Dampak negatif yang dapat terjadi bila sampah rumah sakit tidak di tangani secara baik dan benar yaitu dapat mengakibatkan berbagai macam gangguan antara lain infeksi silang (Nosokomial). Infeksi Nosokomial dapat menyerang pada pengguna rumah sakit yaitu pasien, pengunjung, dan karyawan serta gangguan kesehatan dan keselamatan kerja terutama bagi karyawan rumah sakit bila tidak dilengkapi dengan sistem proteksi yang tepat. Selain itu juga menyebabkan gangguan estetika dan kenyamanan berupa bau, serta kesan kotor yang dapat memberikan efek psikologis bagi pengguna Rumah Sakit. Untuk itu diperlukan pengelolaan yang sesuai dengan karakteristik agar tidak berdampak negatif terhadap lingkungan Rumah Sakit maupun lingkungan sekitarnya

RSUD Ajibarang terletak di Jalan Raya Pancasan, Ajibarang Kabupaten Banyumas. RSUD Ajibarang merupakan Rumah Sakit milik Pemda Banyumas yang memiliki layanan gawat darurat, Rawat Jalan Spesialistik (gigi, syaraf, Penyakit dalam, Kebidanan dan kandungan, Mata, THT, Anak) dan poli umum, Rawat inap, Laboratorium, Radiologi, Farmasi, Pelayanan Kamar Bedah, ICU, dan VCT. Untuk layanan Unit Gawat Darurat siap menerima dan melayani pasien 24 jam. RSUD Ajibarang adalah Rumah Sakit kelas $C$ yang memiliki 163 tempat tidur inap dengan jumlah dokter 20 dokter. Rumah Sakit ini mampu memberikan pelayanan kedokteran spesialis terbatas. Rumah Sakit ini juga menampung pelayanan rujukan dari puskesmas. Pada tahun 2013 volume sampah non medis di RSUD Ajibarang sebesar $\pm 312 \mathrm{~m}^{3}$ sedangkan volume sampah medis sebesar $\pm 10326,86$ $\mathrm{Kg}$ dan sampai saat ini petugas pengelola limbah padat dan limbah cair berjumlah 27 orang. BOR (Bed Occupancy Rate) di RSUD Ajibarang pada tahun 2014 sebesar 56,41\%. Berdasarkan survey pendahuluan yang telah dilakukan, pada pengolahan sampah non medisnya dari tahap penimbulan sampai tahap pembuangan akhir pihak Rumah Sakit belum secara penuh memisahkan atau memilah antara jenis sampah organik dengan sampah anorganik. Kemudian pada pengolahan sampah medisnya tidak ada pengolahan dan pemusnahan sendiri. Pihak Rumah Sakit sudah menyediakan tempat sampah untuk pewadahan sampah organik dan sampah anorganik namun keduanya masih tercampur antara sampah organik dengan sampah anorganik. Hal tersebut dipengaruhi oleh faktor perilaku pengunjung Rumah Sakit yang masih kurang sadar dan kurang memperhatikan jenis pewadahan sampah antara sampah organik dengan sampah anorganik. Sehingga dari tahap penimbulan sampai tahap pembuangan akhir sampah organik dengan sampah anorganik masih tercampur di satu tempat atau pewadahan.

Perumusan masalah, bagaimana pengelolaan sampah medis dan sampah non medis di RSUD Ajibarang

Tujuan, melakukan identifikasi tentang pengelolaan sampah medis dan sampah non medis di RSUD Ajibarang.

\section{BAHAN DAN METODE}

Jenis penelitian adalah Termasuk penelitian deskriptif yaitu menggambarkan fakta yang ada yaitu berupa pengelolaan sampah medis dan sampah non medis dari tahap penimbulan, pewadahan, pengumpulan, pengangkutan, pengolahan, hingga pembuangan akhir di RSUD Ajibarang Kabupaten Banyumas.

Subyek penelitian ini adalah pengelolaan sampah di RSUD Ajibarang yang meliputi penimbulan sampah, penyimpanan sementara, pengumpulan sampah, pemindahan sampah, pengangkutan sampah, hingga pembuangan akhir sampah.

\section{III.HASIL DAN PEMBAHASAN}

Dari hasil penelitian yang telah dilaksanakan pada tanggal 30 Maret -5 april 2015, volume sampah medis di Rumah Sakit Umum Daerah ajibarang Kabupaten Banyumas rata-rata per harinya adalah 736,27 liter.dapat dilihat pada lampiran 1. dan volume sampah non medis rata-rata per harinya adalah 1958,125 liter. Dapat dilihat pada lampiran 2. Pada tahap penimbulan sampah non medis tidak ada pemisahan sesuai jenis sampah yang dihasilkan dan tidak ada pemilahan antar sampah basah dengan sampah kering. Juga tidak ada pemilahan antara sampah yang bisa dimanfatkan kembali namum sudah terdapat minimal 1 buah tempat sampah non medis pada setiap ruangan.

Pada tahap peawadahan, tempat sampah sudah terbuat dari bahan yang kuat, cukup ringan, tahan karat, kedap air, mempunyai permukaan yang mudah dibersihkan pada bagian dalamnya, mempunyai tutup yang bisa dibuka tanpa mengotori tangan, terdapat minimal 1 buah tempat sampah pada setiap kamar atau ruangan, dan sudah dilapisi kantong plastik. Pada penampungan sementaranya sudah dilengkapi dengan saluran cairan lindi, mudah dibersihkan, letaknya mudah dijangkau kendaraan pengangkut 
sampah, kedap air, berpenutup tanpa mengotori tangan dan dikodongkan minimal 1x24 jam.

Sampah medis yang dihasilkan dari Ruang Rawat Inap, IGD, Laboratorium, Rawat Jalan Spesialistik, Poliklinik, Ruang Tindakan, Ruang Farmasi, ICU, Ruang Bedah/ Operasi dikumpulkan di dalam setiap kantong plastik berukuran besar berwarna kuning yang kemudian di simpan ke TPS B3 yang berada di bagian belakang rumah sakit yang terbuat dari semen yang kokoh dan kuat, kedap air, beratap dan berpenutup tanpa mengotori tangan dan terletak pada lokasi yang mudah dijangkau kendaraan pengangkutan sampah. Sedangkan sampah non medis yang dihasilkan dari Ruang Pendaftaran Poliklinik, Ruang Tunggu Poliklinik, IGD, Instalasi Farmasi, Halaman, Selasar, Kantor dan Ruang Rawat Inap, di kumpulkan didalam setiap kantong plastik berukuran besar berwarna hitam yang selanjutnya disimpan ke TPS Non medis yang berada di bagian belakang rumah sakit yang terbuat dari semen yang kokoh dan kuat, kedap air, mudah dibersihkan, beratap, berpenutup tanpa mengotori tangan, dan terletak pada lokasi yang mudah dijangkau kendaraan pengangkut sampah. TPS Non medis dikosongkan sekurang-kurangnya 1x24 jam. Kedua TPS tersebut terletak jauh dari ruang dapur dan ruang perawatan.

Pengangkutan Sampah medis dan sampah non medis dari sumber sampah di lakukan 3 kali dalam satu hari yaitu pada pukul 06.00 WIB, 13.00 WIB dan 16.00 WIB. Pada proses pengangkutan, petugas sudah menggunakan APD dan pengangkutan sudah menggunakan troli tertutup yang mudah dibersihkan, tahan karat, dan terbuat dari bahan yang kuat namun belum melalui jalur khusus. Pengangkutan dilakukan secara manual yaitu mengambil langsung dari sumber sampah di rumah sakit kemudian dimasukan kedalam kantong plastik berwarna hitam untuk sampah non medis dan warna kuning untuk sampah medis selanjutya diangkut dan disimpan di TPS non medis dan di TPS B3 yang kedua TPS tersebut berada di bagian belakang rumah sakit dan jauh dari ruang rawat inap, dapur serta ruangan lainnya. Pengangkutan selanjutnya dilakukan oleh PT Jasa Medivest dan DCKKTR Kabupaten Banyumas diangkut langsung dari TPS untuk dilanjutkan ke tahap pembuangan akhir.

Pada tahap pengolahan sampah medis dan non medis di Rumah Sakit Umum Daerah Ajibarang Kabupaten Banyumas tidak dilakukan. Karena petugas kebersihan hanya mengumpulkan sampah saja dan tidak ada pemilahan sampah yang sesuai dengan ketegorinya. Serta tidak ada upaya untuk mengurangi volume sampah, tidak mengubah bentuk atau memusnahkan limbah padat yang dilakukan pada sumbernya, tidak ada pemanfaatan limbah padat non medis yang masih bisa dimanfaatkan kembali, tidak mengolah limbah padat organik menjadi pupuk, tidak ada pemisahan antara sampah basah dan kering serta organik dengan anorganik karena rumah sakit tidak diperbolehkan mengolah dan memilah sampah medis karena limbah yang sudah masuk kedalam kantong plastik tidak diperbolehkan untuk dibuka kembali karena dapat menimbulkan dampak lain diantaranya yaitu akan menimbulkan sampah berceceran yang akan mengundang vector/binatang pengganggu serta menimbulkan bau jika masih ada sampah yang berceceran. Pengolahan sampah hanya dilakukan oleh pihak lain jika mereka bersedia.

Pada tahap Pembuangan akhir sampah non medis di Rumah Sakit Umum Daerah Ajibarang Kabupaten Banyumas dilakukan setiap hari yaitu pada sekitar pukul 08.00 WIB yang diangkut langsung oleh petugas DCKKTR Kabupaten Banyumas yang selanjutnya akan diangkut dan dibuang ke TPA kaliori atau TPA gunung tugel yang sudah ditetapkan oleh PEMDA Banyumas. Kemudian untuk sampah medis di Rumah Sakit Umum Daerah Ajibarang Kabupaten Banyumas saat ini bekerjasama dengan pihak ketiga yaitu PT JASA MEDIVEST untuk dilakukan pembakaran dan pemusnahan sampah medis yang diangkut tiga kali dalam satu minggu pada jam kerja. Pada pembuangan akhir tidak ada sampah yang tercecer atau tertinggal di dalam TPS.

\section{IV.KESIMPULAN}

1. Pengelolaan sampah di Rumah Sakit Umum Daerah Ajibarang Kabupaten Banyumas dikelola oleh bagian IPAL (Instalasi Pengolahan Air Limbah) sebagai kordinator dan petugas kebersihan sebagai pelaksana.

2. Pengorganisasian pengelolaan sampah di Rumah Sakit Umum Daerah Ajibarang Kabupaten Banyumas sudah mempunyai struktur organisasi yaitu pada IPAL.

3. Pelaksanaan pengelolaan sampah di Rumah Sakit Umum Daerah Ajibarang

a. Rata-rata volume sampah medis sebersar 736,27 liiter/hari dan sampah non medis liter 1958,125 liter/hari

b. Pada sampah non medis masih bercampur antara sampah organik dengan sampah non organik sedangkan pada sampah medis masih ada yang bercampur antara sampah medis tajam dengan sampah medis lainnya.

c. Pada saat pengumpulan dan pengangkutan sampah, petugas kebersihan sudah menggunaka APD.

d. Pengumpulan sampah dari sumber sampah menuju ke TPS masih belum melalui jalur khusus.

e. Pengangkutan dari sumber sampah menuju ke TPS sudah menggunakan gerobak berpenutup.

f. Pengolahan sampah di rumah sakit tidak dilakukan dan tidak ada

g. Pada pembuangan akhir, rumah sakit masih bekerjasama dengan pihak ketiga yaitu PT. Jasa Medivest dan DCKKTR Kabupaten Banyumas. 
h. Skor penilaian pengelolaan sampah medis adalah $89 \%$ dan skor penilaian sampah non medis adalah $77 \%$.

\section{DAFTAR PUSTAKA}

Budiman Chandra, 2007, Pengantar Kesehatan Lingkungan, Jakarta : EGC.

Ferdinan Samuel, 2001, Tinjauan Pengelolaan Sampah Di Rumah Sakit Umum Daerah Prof. Dr. W. Z. Yohannes Kupang 2001, Purwokerto: Depkes R.I, Poltekkes Semarang Jurusan Kesehaatan Lingkungan Purwokerto.

Indonesia, departemen Kesehatan R.I, 1992, Pedoman Sanitasi Rumah Sakit Di Indonesia, Jakarta : Departemen Kesehatan R.I.
,2008, Undang-Undang RI No. 18. Tentang Pengelolaan Sampah, Jakarta : Departement Kesehatan RI

Kuncoro Sejati, 2009, Pengolahan Sampah Terpadu. Yogyakarta : Kanisius (anggota IKAPI).

Sudarso.M.sc, 1985, Pembuangan Sampah, Surabaya : Pusat Pendidikan Tenaga Kesehatan Departemen Kesehatan R.I

,2004, Keputusan Menteri Kesehatan R.I. No : 1204/Menkes/SK/X/2004 Tentang Persyaratan_Kesehatan Lingkungan Rumah Sakit, Jakarta : Departemen Kesehatan R.I.

Tim Penulis Penebar Swadaya,2008, Penanganan dan pengolahan sampah, Jakarta : Penebar Swadaya. 